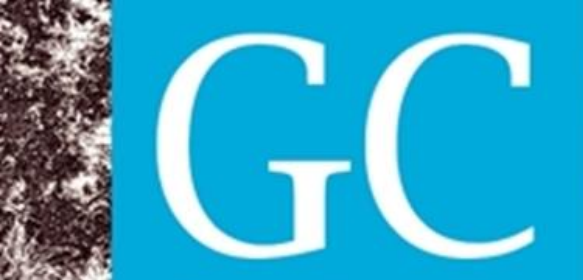

Revista Nacional de

Gerenciamento de Cidades

National Journal of Citiex Management

\title{
O vetor de expansão urbana Araçatuba - Birigui: uma reflexão sobre a produção do espaço urbano
}

The urban expansion vector Araçatuba - Birigui: a reflection on the production of space

El vector de expansión urbana Araçatuba - Birigui: una reflexión sobre la producción del espacio

Ana Paula Cabral Sader 


\section{Resumo:}

Com a aceleração do processo de urbanização no país, vários centros urbanos passaram por transformações importantes, como o fortalecimento dos papeis desempenhados nas redes urbanas e a intensificação das interações espaciais entre diferentes municípios. O processo de interiorização do desenvolvimento econômico deu substrato ao adensamento das interações espaciais e aos processos de articulação no Estado de São Paulo, incorporando novos municípios nas dinâmicas das aglomerações urbanas.

A aglomeração urbana de Araçatuba é constituída por 31 municípios, dos quais destacam-se as cidades de Araçatuba e Birigui, que juntas contam com aproximadamente 315 mil habitantes. O processo de expansão das áreas urbanas de Araçatuba e Birigui vem se intensificando nos últimos vinte anos e esse texto propõe uma breve análise sobre essas cidades a partir de considerações sobre a dinâmica imobiliária e sobre os agentes produtores do espaço urbano.

Palavras-chave: aglomeração urbana; dinâmica imobiliária; cidades médias; Araçatuba; Birigui.

\section{Abstract:}

With the acceleration of the process of urbanization in the country, several urban centers underwent important transformations, such as the strengthening of the roles played in urban nets and the intensification of spatial interactions between different municipalities. The process of internalization of economic development gave substrate to the denser space interactions and articulation processes in the State of São Paulo, incorporating new municipalities in the dynamics of urban agglomerations.

The urban agglomeration of Araçatuba is constituted by 31 municipalities. Of particular note are the cities of Araçatuba and Birigui, which together have approximately 315 thousand inhabitants. The process of expansion of the urban areas of Araçatuba and Birigui has been intensifying in the last twenty years and this text proposes a brief analysis of these cities based on considerations of the real estate dynamics and the producer agentes os urban space.

Key words: urban agglomeration; real estate dynamics; medium-size cities; Araçatuba; Birigui.

\section{Resumen:}

Con la aceleración del proceso de urbanización en el país, varios centros urbanos pasaron por transformaciones importantes, como el fortalecimiento de los papeles desempeñados en las redes urbanas y la intensificación de las interacciones espaciales entre diferentes municipios. El proceso de interiorización del desarrollo económico dio sustrato al adensamiento de las interacciones espaciales ya los procesos de articulación en el Estado de São Paulo, incorporando nuevos municipios en las dinámicas de las aglomeraciones urbanas.

La aglomeración urbana de Araçatuba está constituida por 31 municipios, de los cuales se destacan las ciudades de Araçatuba y Birigui, que juntas cuentan con aproximadamente 315 mil habitantes. El proceso de expansión de las áreas urbanas de Araçatuba y Birigui se ha intensificado en los últimos veinte años y este texto propone un breve análisis sobre esas ciudades a partir de consideraciones sobre la dinámica inmobiliaria y sobre los agentes productores del espacio urbano.

Palabras clave: aglomeración urbana; dinámica inmobiliaria; ciudades medias; araçatuba; Birigui. 

Harvey (2004a, 2004b) e Soja (1993) construíram a noção de "desenvolvimento geograficamente desigual", a partir da qual explicam as diferenciações socioespaciais e defendem a existência de uma sociedade de classe que diferencia as pessoas a partir do lugar que ocupam tanto na produção quanto na distribuição da riqueza gerada, além de considerar o papel da divisão espacial do trabalho como elemento diferenciador dos lugares.

Sobre desenvolvimento geográfico desigual, Harvey (2004a, p. 110-112) escreve:

\begin{abstract}
O exame do mundo em qualquer escala particular revela de imediato toda uma série de efeitos e processos que produzem diferenças geográficas nos modos de vida, nos padrões de vida, nos usos dos recursos, nas relações com o ambiente e nas formas políticas e culturais. [...] Mas as diferenças geográficas são bem mais do que legados histórico-geográficos. Elas estão sendo perpetuamente reproduzidas, sustentadas, solapadas e reconfiguradas por processos político-econômicos e socioecológicos que ocorrem no momento presente. [...] Mas os processos de diferenciação são tão ecológicos e sociais quanto puramente econômicos. [...] Essas mudanças tornaramse, no entanto, em épocas recentes, mais voláteis, em parte porque ocorreram mudanças qualitativas no âmbito do próprio processo de globalização. [...] A concepção geral de desenvolvimento geográfico desigual que tenho em mente envolve uma fusão destes dois elementos, a mudança das escalas e a produção de diferenças geográficas.
\end{abstract}

A prática social é espacializada e a ação envolve espaço e tempo, realizando-se em várias escalas indissociáveis a partir do plano do lugar. Na cidade, segundo Carlos (2007), revela-se como justaposição entre uma morfologia social (promovida pela diferenciação das classes na sociedade) e pela morfologia espacial (produzida pelas diferenças nas formas e modos de acesso aos espaços da vida, através do uso). Para Carlos (2007, p. 49):

\footnotetext{
O desenvolvimento histórico da propriedade no seio do processo de reprodução aponta a reprodução do valor de troca - e o que dela se diferencia, o que ela subordina e como orienta o uso como possibilidade de apropriação realizando-se como diferença. [...] Nesse sentido, a escala do local e da cidade contempla como determinação a negatividade manifesta no plano da vida cotidiana que aparece como o lugar dessa realização. É a escala do habitar que surge e realiza o diferente em sua determinação negativa quando se define pelo conflito e pela luta em torno das apropriações diferenciadas do espaço, e como reivindicação para o uso (tal qual se revela nas cidades hoje).
}

Como argumenta Sposito (2013), a diferenciação socioespacial não se revela apenas nos espaços residenciais, mas inclui outros espaços da vida social, como os relacionados ao trabalho e ao lazer, tendo em vista as possibilidades de mobilidade espacial e de comunicação, muito diferentes segundo as condições socioeconômicas de diferentes segmentos sociais.

Não por acaso, shopping centers, hipermercados, centros de eventos e negócios, grandes hotéis e outros espaços de oferta de bens e serviços de maior preço no mercado têm estratégias de localização espacial que se orientam por essas possibilidades e reforçam as 


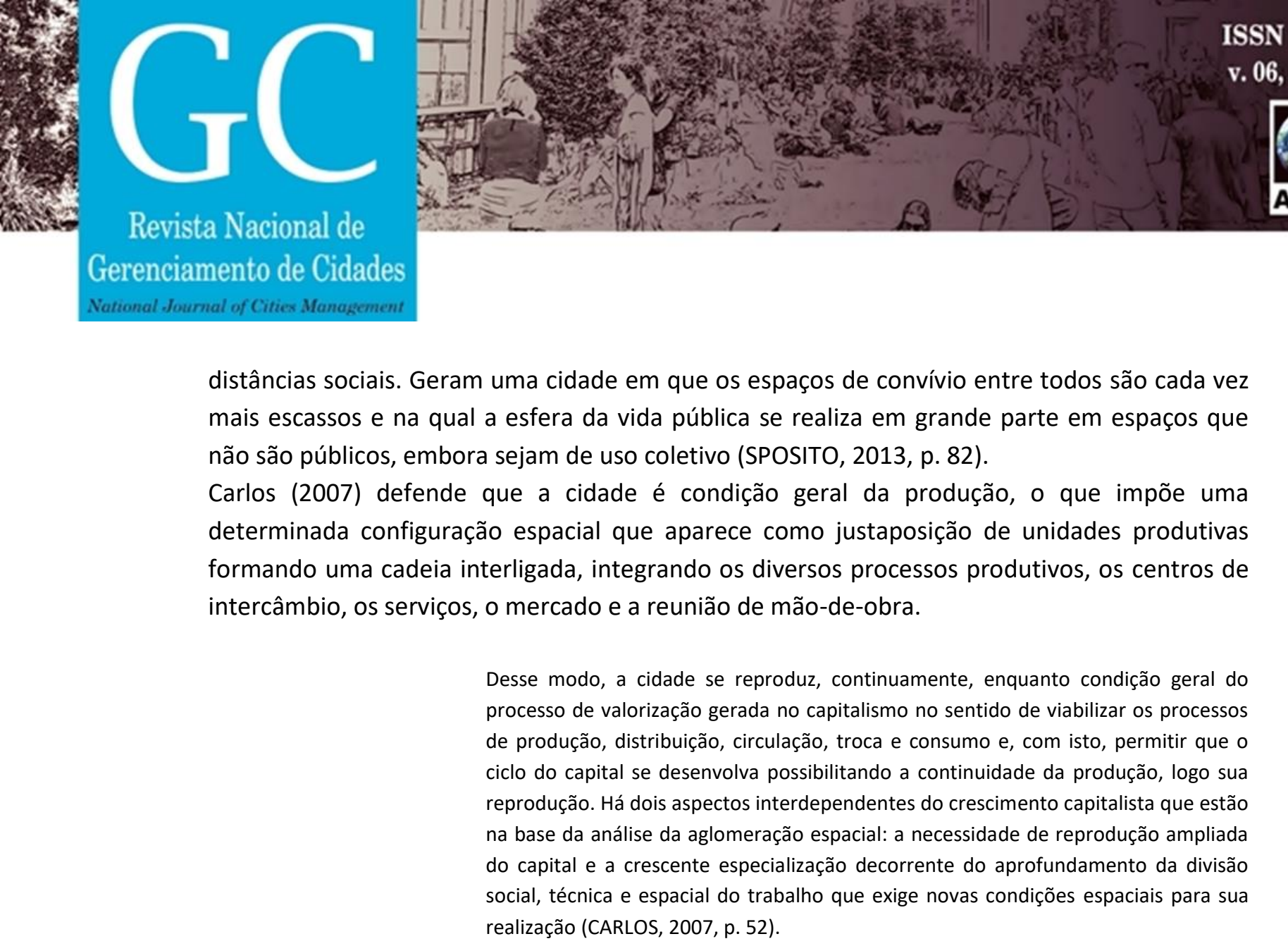

\section{A DINÂMICA IMOBILIÁRIA E OS AGENTES PRODUTORES DO ESPAÇO URBANO}

Ao iniciar a construção teórica do processo de produção do espaço, Harvey (2013) afirma que a base fundiária (valor da terra) é sustentação - e contradição - do capitalismo. Ainda segundo Harvey (2004a, 2004b), a partir da noção do "desenvolvimento geograficamente desigual", a localização é o momento vital dentro da circulação e da acumulação, no capitalismo.

Assim, pode-se dizer que a produção do espaço realiza-se enquanto condição, meio e produto da sociedade capitalista que, por sua vez, repousa na desigualdade, fundamento histórico do capitalismo (CARLOS, 2007, p. 57-58).

Campos (1989) destaca a existência de um meio de produção - o solo urbano - sobre o qual se processa a edificação. $O$ terreno entra na circulação indissoluvelmente unido à mercadoria produzida "edifício", o que nos traz que "a renovação do ciclo do capital construtor dependerá da superação do obstáculo da propriedade". Isso determina o aparecimento do capital incorporador, um novo agente no circuito de produção imobiliária, que viabiliza o acesso do capital construtor ao solo-suporte de seu processo produtivo. O capital incorporador tem poder de decisão sobre o uso futuro do solo urbano, elemento organizador do circuito imobiliário. São os capitais incorporadores que assumem o controle econômico do processo de produção da moradia, definindo as características da mercadoria produzida, sua demanda potencial, estratégias de venda e localização.

São as decisões de investimento dos capitais incorporadores que determinam os processos de produção capitalista dos estoques imobiliários urbanos. Além do capital construtor, o ciclo se completa com a presença dos capitais de empréstimo que financiam a produção da mercadoria habitação. $O$ capital incorporador tem no ganho fundiário o componente principal de seu lucro, o que estabelece uma ligação estrutural entre o processo de valorização desses 


relativamente à materialidade dos aspectos de organização funcional quantitativa e dos aspectos qualitativos e figurativos". Há estudos na Geografia que abordam a questão da produção do espaço urbano a partir de análises pautadas nos elementos constituintes da morfologia, como o plano e a sua evolução; as relações do plano com o sítio urbano; a fisionomia urbana; a densidade da ocupação, a identificação de áreas morfologicamente homogêneas; a heterogeneidade das formas.

De acordo com Lamas (2014, p. 38 e 39), a morfologia urbana é:

[...] o estudo da forma do meio urbano nas suas partes físicas exteriores, ou elementos morfológicos, na sua produção e transformação no tempo [...]. Um estudo da morfologia urbana ocupa-se da divisão do meio urbano em partes [...] e da articulação destes entre si com o conjunto que definem [...]. O que remete para a necessidade de identificação e clarificação dos elementos morfológicos, quer em ordem à leitura ou análise do espaço quer em ordem à sua concepção ou produção [...]. Um estudo do morfológico deve necessariamente tomar em consideração os níveis ou momentos de produção do espaço urbano.

Roncayolo (1990) contribui para o debate colocando a noção de morfologia não apenas como simples geometria, mas tomando a forma como ponto de partida para discutir e desvendar conteúdos. E a relação dialética coloca-se novamente: ler a forma (empírico) para entender processos (abstrato); analisar processos para entender a forma.

Para proceder a uma adequada leitura da forma urbana deve-se procurar separar os aspectos formais (sítio, forma urbana, densidade, paisagem, etc...), dos aspectos funcionais (legislação urbana, uso do solo, identificação das áreas de moradia, circulação, comércio, produção), numa análise que contemple a relação dialética processo/forma e forma/processo.

Assim, a análise da forma e da morfologia urbana, considerando-se a dinâmica do processo de produção do espaço urbano, torna-se fundamental para a compreensão das transformações das cidades nas suas dimensões territorial, populacional e em relação aos seus papéis regionais e funções urbanas. Na medida em que os diferentes elementos que constituem a morfologia urbana são resultantes das ações e interesses de determinados agentes, entendese que a constituição das diferentes formas espaciais parte da compreensão de suas transformações ao longo do tempo, segundo as ações e os interesses desses agentes, reforçando a perspectiva da reestruturação urbana e da cidade.

Santos (1978) aborda a relação forma-conteúdo na qual as formas não existem por si só, pois apresentam conteúdos resultantes das dinâmicas e lógicas espaciais e temporais. Assim, forma e conteúdo têm papel ativo no movimento do todo social. Reforça-se, então, o entendimento de que a análise temporal é fundamental, pois como destacou Sposito (2005, p. 66):

[...] o conceito de morfologia urbana não se referiria a uma dada forma urbana (extensão e volume), tal como ela se apresenta configurada espacialmente, mas ao processo de sua gênese e desenvolvimento, segundo os quais podemos explicar essa morfologia e não apenas descrevê-la ou representá-la gráfica ou cartograficamente. 



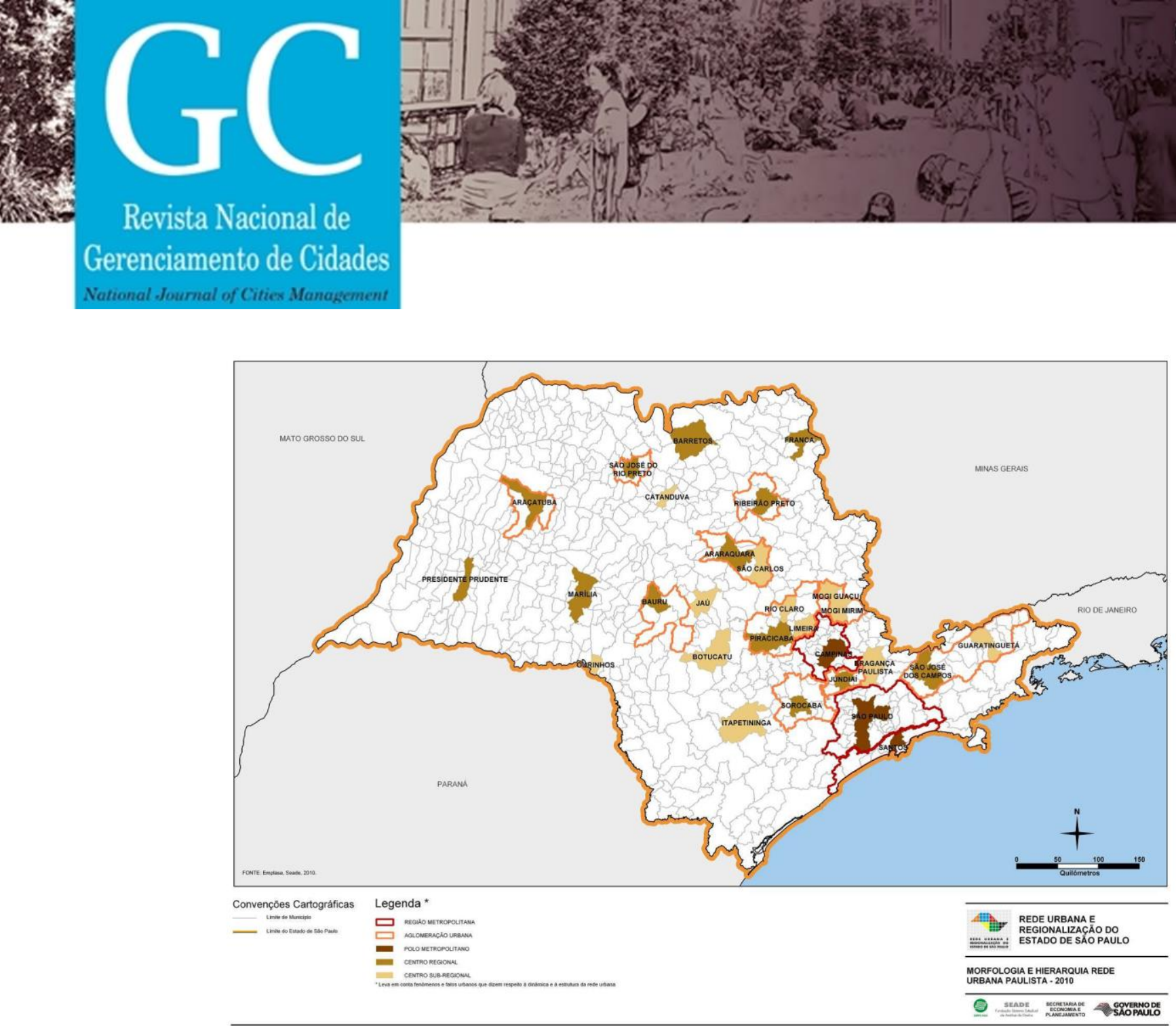

Mapa 3 - Morfologia e Hierarquia da Rede Urbana Paulista - 2010

Fonte: Estudo da morfologia e hierarquia funcional da rede urbana paulista e regionalização do Estado de São Paulo
-
Extrato
Documento
2
Resultados.
Disponível
em:

http://www.emplasa.sp.gov.br/emplasa/ProjetosEstudos/Relatorios/SEMINARIO REDREG D2 Final.pdf.

Acesso em 20.12.2017.

O conceito de aglomeração urbana adotado neste estudo fundamenta-se no reconhecimento e análise de fatos urbanos caracterizados "[...] pela concentração de população, relevância econômico-social e forte articulação, explicitados em uma mancha urbana conurbada, ou com forte tendência à conurbação, e em intensos fluxos de pessoas, bens e serviços" (SÃO PAULO, 2011, p. 17).

O conceito de aglomeração urbana contempla ainda

[...] a existência de relações funcionais, representadas pelas trocas funcionais entre municípios, identificadas por deslocamentos pendulares, motivados por acesso à escola e ao trabalho, bem como pelo acesso aos serviços de saúde. Também contemplou a identificação/presença de municípios-polo e de subpolos, que estruturam as relações de interação e/ou integração funcional com os centros urbanos de sua área de influência (SÃO PAULO, 2011, p. 28).

Segundo dados do Instituto Brasileiro de Geografia e Estatística (IBGE), a cidade de Araçatuba é considerada uma Capital Regional $C$, com economia predominantemente voltada à produção agropecuária, com destaque para a carne bovina e o setor sucroalcooleiro. Teve sua população 
estimada em 192.757 no ano de 2015, área da unidade territorial da ordem de $1.167 \mathrm{~km}^{2} \mathrm{e}$ densidade demográfica de 155,54habitantes $/ \mathrm{km}^{2}$. A cidade de Birigui, com economia voltada à produção calçadista, conta com uma população estimada em 118.352 (2015), área da unidade territorial da ordem de $530 \mathrm{~km}^{2}$ e densidade demográfica de 204,79 habitantes $/ \mathrm{km}^{2}$.

$O$ processo de expansão das áreas urbanas de Araçatuba e Birigui vem se intensificando nos últimos vinte anos (Figuras 1 e 2) e a Rodovia Marechal Rondon (SP-300) apresenta-se como sua principal via de ligação, além de fundamental meio de escoamento de sua produção.

A Avenida dos Araçás, um dos principais eixos viários de Araçatuba, possibilitou o espraiamento da cidade, constituindo um anel viário que interliga as Avenidas Waldemar Alves, Waldir Felizola de Moraes e Joaquim Pompeu de Toledo, as duas últimas se conectando na direção da Rodovia Teotônio Vilela, que separa, em 20 quilômetros, as cidades de Araçatuba e Birigui. Nesse intermédio existem hospitais, universidades e condomínios residenciais fechados, entre eles o Alphaville. Os empreendimentos ao longo dessa rodovia visam atender ao público dessas duas cidades. 
Até o final do ano de 2017, foram entregues 3.933 unidades residenciais da Faixa 1 do Programa Minha Casa Minha Vida - MCMV, principalmente nas Zonas Oeste e Norte do município de Araçatuba (Bracioli, 2017). Também se verifica na cidade uma combinação entre áreas de ocupação popular, com construções da Faixa 2 do MCMV, no Bairro Concórdia (Zona Sudeste) e um concomitante processo de valorização de áreas vizinhas (R. Baguaçú / Rodovia Teotônio Vilela), no caminho para Birigui. Existe a junção do capital local e externo na construção de shopping centers e capital externo na construção de condomínios residenciais horizontais fechados, hotéis e supermercados. Assim, algumas questões podem ser delineadas. Quem produz esse espaço urbano? Qual o significado da combinação ocupação popular e o simultâneo processo de valorização dessas áreas? Quais são os agentes que estão promovendo a transformação da cidade? Segundo a noção de "desenvolvimento geograficamente desigual" de Harvey (2004a, 2004b), pode-se falar em diferenciação socioespacial nessas áreas? De que modo as decisões de investimento dos incorporadores alteram a estrutura urbana da cidade, intensificando os processos de diferenciação e desigualdades socioespaciais?

O processo de reestruturação econômica, através da cadeia produtiva sucroalcooleira e do atendimento às suas demandas no setor terciário, produz alterações nas escolhas locacionais, nas formas de organização da produção e de distribuição das mercadorias, compondo um quadro de reestruturação produtiva com rebatimentos na economia e nas práticas sociais. As mudanças em curso requerem redefinição nas formas de produção do espaço urbano, o que inclui o uso e a apropriação deles para que atendam às demandas dos novos agentes econômicos, gerando a procura de novos espaços de consumo e de habitação. Desse modo, é fundamental para a leitura e entendimento dos processos em curso em Araçatuba, a análise da associação entre mudanças na economia e mudanças no espaço, além da articulação entre processos e formas. Segundo Carlos (2007, p. 54), a produção do espaço desdobra-se a partir do viés econômico, político e social:

[...] do ponto de vista econômico se produz sob a racionalidade da busca do lucro e do crescimento; no plano do político, sob a lógica do planejamento que normatiza e instrumentaliza o espaço; no plano social revela a vida, e desse modo a sociedade em seus conflitos, pois o econômico e o político se realizam na vida cotidiana e no lugar com estratégias específicas que se confrontam com as necessidades da vida humana.

Este estudo preliminar sugere que as lógicas e interesses inerentes ao processo de produção do espaço têm levado à constituição de formas urbanas associadas a uma estrutura cada vez mais complexa no que se refere aos conteúdos, usos e configurações territoriais, verificandose transformações que tendem a intensificar processos de diferenciação socioespacial. 

diferentes contextos espaciais no âmbito da morfologia urbana como um pertinente meio para a compreensão das transformações que ocorrem no espaço urbano, evidenciando os processos que atuam na dinâmica espacial e temporal.

\section{REFERÊNCIAS}

BRACIOLI, Márcio. Minha Casa Minha Vida ajudou mais a classe média de Araçatuba em 8 anos. Folha da Região, Araçatuba, 18 out.2017. Disponível em: http://www.folhadaregiao.com.br/ara\%C3\%A7atuba/minha-casa-minhavida-ajudou-mais-a-classe-m\%C3\%A9dia-de-ara\%C3\%A7atuba-em-8-anos-1.368400 . Acesso em: 13 mar.2018.

CAMPOS, Pedro Abramo. A dinâmica imobiliária: elementos para o entendimento da espacialidade urbana. In: Cadernos IPPUR/UFRJ, ano III, n. especial, dez. 1989. Rio de Janeiro: UFRJ, 1989, pg. 47-70.

CARLOS, Ana Fani Alessandri. Diferenciação socioespacial. Cidades, v. 4, n. 6, 2007, p. 45-60.

Disponível em: http://revista.fct.unesp.br/index.php/revistacidades/article/viewFile/569/600 . Acesso em: 15 dez.2017.

CORRÊA, Roberto Lobato. Trajetórias geográficas. Rio de Janeiro: Bertrand Brasil, 2001.

. O Espaço Urbano. São Paulo: Editora Ática, 2005.

HARVEY, David. Espaços de esperança. São Paulo: Loyola, 2004a.

. A produção capitalista do espaço. São Paulo: Annablume, 2004b.

. Os limites do capital. São Paulo: Editora Boitempo, 2013. Cap. 5, 8, 9, 10, 11 e 12.

IBGE - Instituto Brasileiro de Geografia e estatística. Brasil em síntese - São Paulo, 2017. Disponível em: https://cidades.ibge.gov.br/brasil/sp/aracatuba/panorama. Acesso em: 13 dez.2017.

LAMAS, José M. R. G. Morfologia urbana e desenho da cidade. Lisboa: Fundação Calouste Gulbenkian, 2014.

RONCAYOLO, M. La ville et ses territoires. Paris, Gallimard, Folio Essais, 1990.

RONCAYOLO, M. Les grammaires d'une ville: essai sur la genèse des structures urbaines à Marseille. Paris, Éd. De l'École des hautes études en sciences sociales, 1996.

SANTOS, M. Por uma geografia nova. São Paulo: Editora Hucitec, 1978.

SÃO PAULO (Estado). Secretaria de Estado de Economia e Planejamento; EMPLASA; SEADE. (Coord.). Estudo da morfologia e hierarquia funcional da rede urbana paulista e regionalização do Estado de São Paulo - Extrato Documento 2 - Resultados. São Paulo: Governo do Estado de São Paulo, 2011.

SMITH, Neil. Desenvolvimento desigual: natureza, capital e a produção de espaço. Rio de Janeiro: Bertrand Brasil, 1988.

SOJA, Edward. Geografias Pós-modernas: a reafirmação do espaço na teoria social crítica. Rio de Janeiro: Jorge Zahar Editor, 1993. 
SPOSITO, Maria Encarnação Beltrão. NOVOS CONTEÚDOS NAS PERIFERIAS URBANAS DAS CIDADES MÉDIAS DO ESTADO DE SÃO PAULO, BRASIL. In: Investigaciones Geográficas,

número 054. Universidad Nacional Autónoma de México, Distrito Federal, México, 2004. p. 114-139.

O chão aos pedaços. Economia, urbanização e cidades no Estado de São Paulo. Tese (Livre Docência), Unesp, Presidente Prudente-SP, 2005.

Lógicas Econômicas e Práticas Espaciais Contemporâneas: Cidades Médias e Consumo. Projeto de Pesquisa do Programa de Pós-Graduação em Geografia da UNESP - Campus de Presidente Prudente. Presidente Prudente: UNESP, 2011.

A produção do espaço urbano: escalas, diferenças e desigualdades socioespaciais. In: CARLOS, Ana Fani Alessandri; SOUZA, Marcelo Lopes; SPOSITO, M. Encarnação B. (org.). A produção do espaço urbano: agentes e processos, escalas e desafios. São Paulo: Contexto, 2013. p. 123-145.

WHITACKER, A.; MIYAZAKI, V. (RE)ESTRUTURAÇÃO URBANA E DA CIDADE: UM ESTUDO SOBRE FORMA E MORFOLOGIA URBANA EM CIDADES DE PORTE MÉDIO. In: XII Seminário da Red Iberoamericana de Investigadores sobre Globalización y Territorio (RII), 2014, Salvador. Disponível em:

http://www.rii.sei.ba.gov.br/anais_xiii/gt6/GT6_VITOR.pdf. Acesso em 22 jan.2017. 